(C) 1984. The Genetical Society of Great Britain

\title{
RESTRICTION ENDONUCLEASE MAP VARIATION AND GENE ACTIVITY IN THE ADH REGION IN A POPULATION OF DROSOPHILA MELANOGASTER
}

\author{
A. J. BIRLEY \\ Department of Genetics, University of Birmingham, P.O. Box 363, \\ Birmingham B15 2TT, England
}

Received 21.vii.83

\section{SUMMARY}

\begin{abstract}
Variation within a $12 \mathrm{~kb}$ region containing the $A d h$ gene was studied in 16 highly inbred lines of independent extraction from a population of Drosophila melanogaster, "Texas". Out of a selection of 8 hexanucleotide specific restriction endonucleases, four restriction site and five DNA insertion/deletion variations were observed and the heterozygosity per nucleotide was 0.004. Linkage disequilibrium between two restriction sites, considerably removed from and on either side of the $A d h$ transcriptional unit, identified two major classes of chromosome or haplotype in the population. These two haplotypes were strongly associated with the capacity of lines to respond to the environment (genotypeenvironment interaction) in ADH activity. It was concluded that a control or regulatory polymorphism was present in the population in association with the Adh transcriptional unit.
\end{abstract}

\section{INTRODUCTION}

The cloning of eukaryote DNA which contains the coding sequences of known genes potentially permits both a molecular analysis of the mechanism of gene expression as well as an assessment of the relationship, if any, between variations in coding and non-coding DNA of the different individuals in a population. The mapping of variations in nucleotide sequences in cloned genomic or mitochondrial DNA with restriction endonucleases has now been used in a number of evolutionary studies of variation within populations and between species. Examples are provided by the $\beta$-globin cluster in man (Jeffreys, 1979; Antonarakis, Orkin, Kazazian, Goff, Boehm, Waber, Sexton, Ostrer, Fairbanks and Chakravarti, 1982; Orkin, Kazazian, Antonarakis, Goff, Boehm, Sexton, Waber and Giardina, 1982), the Adh region of Drosophila species (Langley, Montgomery and Quattlebaum, 1982), mitochondrial DNA of Drosophila species (Shah and Langley, 1979), and of the deer mouse, Peromyscus (Avise, Lansman and Shade, 1979). Restriction endonuclease mapping allows a relatively quick survey of large segments of DNA in many strains or individuals. As well as identifying restriction site or individual DNA base variations, the technique also identifies large insertions and deletions of DNA, relative to a standard sequence, in a selected section of DNA.

This study is of variations between 16 highly inbred lines of Drosophila melanogaster, derived from a single population "Texas", in the restriction map of $12 \mathrm{~kb}$ region of DNA which contains the coding sequences for the enzyme Alcohol dehydrogenase (ADH). The set of lines had been previously characterised with respect to several aspects of $A d h$ gene activity, namely ADH enzyme activity, the level of immunologically cross-reacting material 
specific to the ADH enzyme, Michaelis constants, aspects of gene interaction in expression, dominance and genotype-environment interaction (Birley, Marson and Phillips, 1980; Birley and Marson, 1981; Birley, Couch and Marson, 1981). The study is the first to report an association, within a population, of variation in restriction map and gene expression.

\section{Materials AND METHOdS}

(i) The inbred lines

Details of the 16 lines, highly inbred by brother-sister mating for over 120 generations and extracted from a large laboratory population, "Texas" are given in Birley and Barnes (1975) and in Birley, Couch and Marson (1981). Adults were reared on standard food medium (Birley et al., 1982) at $25^{\circ}$, harvested and stored at $-70^{\circ}$.

\section{(ii) DNA extraction and purification}

DNA was extracted from 1-1.5 gm of frozen material using $\mathrm{CsCl}_{2}$ gradient centrifugation at $55,000 \mathrm{rpm}$ for 72 hours at $15^{\circ}$ in a Beckman $63 \mathrm{Ti}$ rotor. Preparation of DNA for centrifugation followed a path of nuclear isolation and nuclear lysis in 2 per cent sodium $\mathrm{N}$-lauryl sarcosine. After centrifugation the DNA was subjected to exhaustive dialysis against Tris $(10 \mathrm{mM})$-HCl-EDTA $(1 \mathrm{mM}) p \mathrm{H} \mathrm{7 \cdot 5}$. Further details of the technique are to be found in Bingham, Levis and Rubin (1981).

\section{(iii) Restriction endonuclease digestion}

DNA was digested with restriction endonucleases at $37^{\circ}$ in conditions recommended by the supplier (Bethesda Research Laboratories). Eight restriction endonucleases all specific for different hexanucleotide sequences were used. The enzymes were BamHI, EcoRI, HindIII, Hpa-I, Pst-I, Sal-I, $X b a-I, X h o-I$. Electrophoresis of single and double endonuclease digests was carried out in 1 per cent agarose gels in a BRL, 44 gel apparatus. The continuously circulated buffer was standard $1 \times \mathrm{TBE}$; Tris $(89 \mathrm{mM})$-boric acid $(89 \mathrm{mM})$-EDTA $(2.5 \mathrm{mM})$ and low voltage $\left(1.5\right.$ volts $\left.\mathrm{cm}^{-1}\right)$ gradients were used (McDonnell, Simon and Studier, 1977) to separate the DNA fragments.

\section{(iv) Detection of specific DNA sequences}

DNA was transferred to nitrocellulose sheets (BRL) using the principles of Southern (1975). The pBR322 based on sAS-1 plasmid (Goldberg, 1980) was labelled with $\alpha^{32} \mathrm{P} \mathrm{dCTP}, 3000 \mathrm{Ci} \mathrm{mM} \mathrm{mM}^{-1}$ (Amersham International) by nick-translation (Rigby, Diekmann, Rhodes and Berg, 1977) and hybridisation carried out in the presence of dextran sulphate (Wahl, Stern and Stark, 1979). Autoradiography followed with Kodak X-Omat RP film for 24-48 hours at $-70^{\circ} \mathrm{C}$.

\section{(v) Molecular weight determination}

Molecular weights were determined using a Summagraphics digitiser interfaced with the University of Birmingham DEC-20 computer. The computer programme was developed and kindly made available by 
W. Quattlebaum (Genetics Section, National Institute of Environmental Health Sciences, North Carolina). Computational details are given in Schaffer and Sederoff (1980).

\section{Results}

The basic restriction map was, as in the study by Langley et al. (1982), not dissimilar from that of the SAF-2 clone of Goldberg (1980); this is the restriction map presented in Fig. 1. To facilitate comparison with the work of Langley et al. (1982), the species invariant BamHI site in the second exon of the $A d h$ transcriptional unit has been given the co-ordinate of $0 \cdot 0$. Restriction sites within the probed region will be referred to in relation to this co-ordinate.

Variation for both restriction sites and for large DNA insertions and deletions was present in the "Texas" inbred lines. Restriction site polymorphism was observed at four positions, PstI $(-6 \cdot 2)$, Hind III $(-3 \cdot 0)$, XhoI $(+1 \cdot 2)$ and $B a m \mathrm{HI}(+1 \cdot 5)$. Variants at or very close to the HindIII and XhoI sites have been described previously by Langley et al. (1982). PstI and BamHI sites were not present within the sAS-I probe and are characteristic of this population. Five types of DNA insertion or deletion were present. Two insertions were large, $\Delta 3700 \mathrm{~kb}$ and $\Delta 2300 \mathrm{~kb}$, and one insert $\Delta 350 \mathrm{~kb}$ was polymorphic in some lines (lines 3 and 27 ) and fixed in three others (lines 7, 18 and 28). Line 19 presented three major insertion/deletion variants.

Estimates of genetic variability for the region were obtained using the estimators of Ewens, Spielman and Harris (1981). The proportion of nucleotide sites which are polymorphic is 0.012 and the estimate of heterozygosity per nucleotide is 0.004 . When considered as a whole, the heterozygosity for restriction sites, in the entire probed region is $0 \cdot 86$, estimated according to Nei and Tajima (1981).

Tests of linkage disequilibrium were carried out on the six $2 \times 2$ combinations of polymorphic restriction sites with Fisher's exact test (table 1). A test for linkage disequilibrium in relation to $A d h^{F}$ and $A d h^{s}$ alleles was not carried out since the sample contained only two $A d h^{F / F}$ lines and would in that case be insensitive. Strong linkage disequilibrium was shown amongst three of the four restriction site polymorphisms, HindIII $(-3 \cdot 0)$, Xho-I $(+1 \cdot 2)$ and $\mathrm{Bam} \mathrm{HI}(+1 \cdot 5)$.

Possible relationships between genetical architectures in the set of lines and gene activity were investigated by relating previously published estimates of mean $\mathrm{ADH}$ activity and $\mathrm{ADH}$ protein level (level of $\mathrm{ADH}$ cross-reacting material), (Birley, Couch and Marson, 1981) to restriction site polymorphism. This approach was also carried out for the comparative response of lines in genotype-environment interaction for $\mathrm{ADH}$ activity (Birley and Marson, 1981). There was no evidence of an association between the mean $\mathrm{ADH}$ activity or mean $\mathrm{ADH}$ protein level and any of the four restriction site polymorphisms. This is not surprising since ADH activity is controlled in this population (Barnes and Birley, 1978) as well as in other populations (McDonald and Ayala, 1978; Laurie-Ahlberg, Maroni, Bewley, Lucchesi and Weir, 1980), by loci which are located upon different chromosomes (I and III) from that upon which the Adh structural gene (chromosome II) is located. 


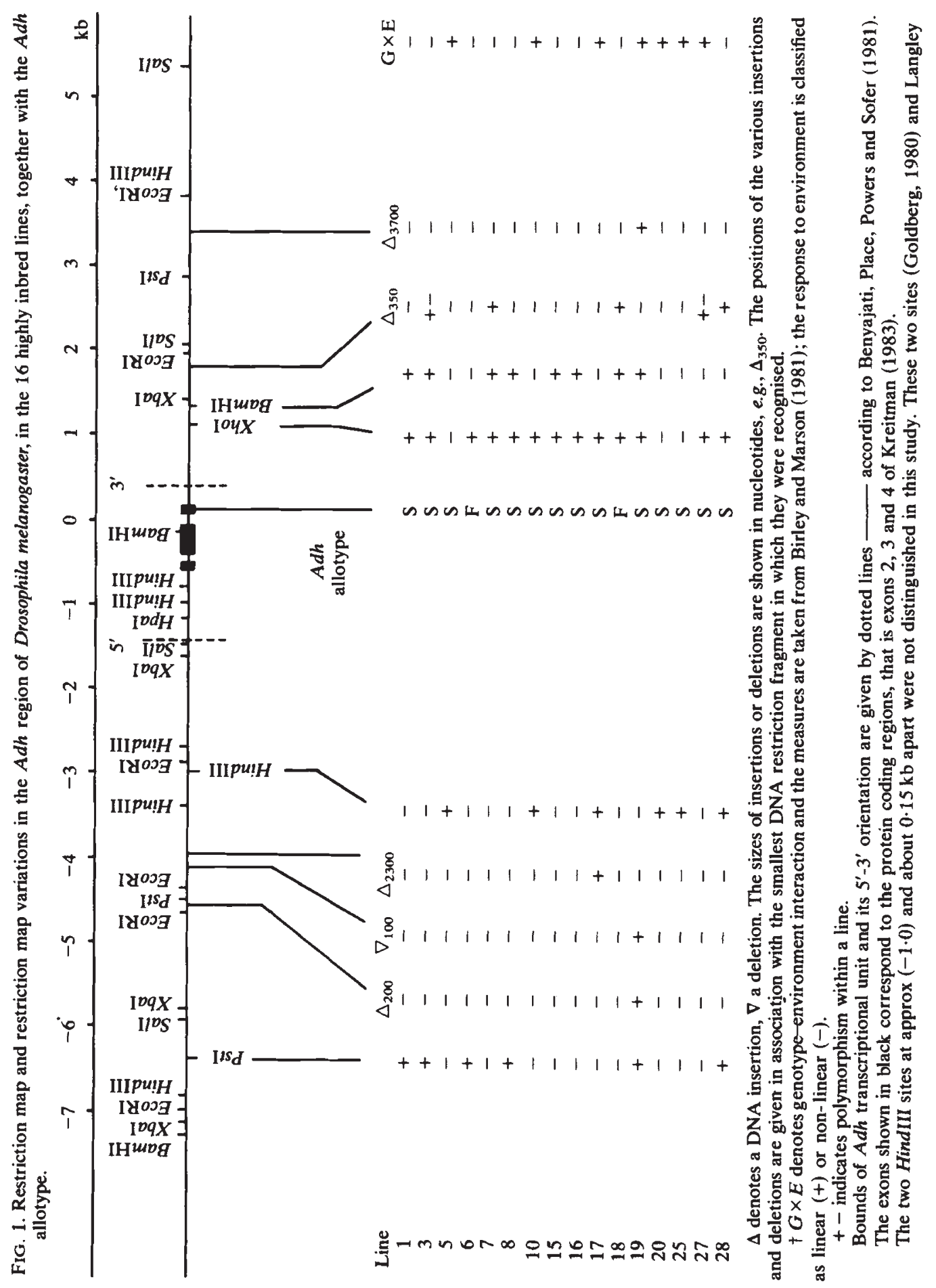


TABLE 1

Probabilities, given by Fishers' exact test for a $2 \times 2$ contingency table, for linkage disequilibrium between restriction site polymorphisms

\begin{tabular}{cc}
\hline Restriction site combination & $P$ \\
\hline Pst $-\mathrm{I} /$ Hind III & $0 \cdot 189$ \\
Pst $-\mathrm{I} /$ Bam HI & $0 \cdot 330$ \\
Pst-I/ Xho-I & $0 \cdot 214$ \\
HindIII/Bam HI & $0 \cdot 003$ \\
HindIII/Xho-I & $0 \cdot 036$ \\
Bam HI/ Xho-I & $0 \cdot 100$ \\
\hline
\end{tabular}

Genotype-environment interaction for ADH activity has been previously assessed in the set of inbred lines (Birley and Marson, 1981) by the methods of biometrical genetics (Perkins and Jinks, 1968; Pooni and Jinks, 1980). In summary, the methods compare the performance of the set of inbred lines in a set of different environments, the measure of various environments being in this case purely biological and provided by the average performance of all lines. Two distinct forms of genotype-environment interaction can be distinguished from the survey of the "Texas" inbred lines (Birley and Marson, 1981); linear and non-linear. Lines classified as linear show a simple response to the environment which is largely linear. Lines classified as non-linear show a complex or inconsistent response to the environment. The classification of the set of inbred lines according to their response to the environment is shown in fig. 1 and the relationship between restriction site polymorphism and genotype-environment interaction is shown in table 3 as probabilities for Fishers' exact test for association in a $2 \times 2$ contingency table. Two restriction sites (Hind III $(-3.0)$ and $B a m \mathrm{HI}(+1 \cdot 5))$ are associated with the type of response to the environment. Interestingly, it is these two restriction sites which show the most marked linkage disequilibrium (table 2), one (HindIII $(-3 \cdot 0)$ ) on the $5^{\prime}$ side and the other (BamHI $(+1 \cdot 5))$ on the $3^{\prime}$ side of the Adh transcriptional unit (fig. 1). This particular association of restriction sites defines two major classes of haplotype in the population (table 3). The association between the two types of chromosome and type of genotype-environment interaction is strong $(P=0 \cdot 016$; Fishers' exact test $)$. Hence the population of inbred

TABLE 2

Restriction site polymorphism and genotype-environment interaction for ADH activity. The observed numbers of lines falling into the four categories of restriction site polymorphism (+or-) and genotype-environment interaction response, depicted here as linear $\left(t^{\prime}\right)$ and non linear $\left(-^{\prime}\right)$, are given together with probabilities from Fishers' exact test for association in a $2 \times 2$ contingency table

\begin{tabular}{ccccccc}
\cline { 1 - 3 } Restriction site & $++^{\prime}$ & $+^{\prime}$ & $-+^{\prime}$ & $--^{\prime}$ & $P$ \\
\cline { 1 - 2 } Pst $\mathrm{II}$ & 1 & 5 & 6 & 4 & $0 \cdot 110$ \\
Hind III & 5 & 1 & 2 & 8 & $0 \cdot 024$ \\
Xho-I & 4 & 9 & 3 & 0 & $0 \cdot 062$ \\
Bam HI & 1 & 7 & 6 & 2 & $0 \cdot 020$ \\
\hline
\end{tabular}


TABLE 3

Linkage disequilibrium between the polymorphic HindIII and BamHI restriction sites and type of genotype-environment interaction

\begin{tabular}{cccc}
\hline \multicolumn{2}{c}{ Restriction site } & \multicolumn{2}{c}{$\begin{array}{c}\text { Genotype-environment } \\
\text { interaction }\end{array}$} \\
\hline HindIII & Bam HI & Linear & Non-Linear \\
\hline+ & + & 0 & 0 \\
+ & - & 5 & 1 \\
- & + & 1 & 7 \\
- & - & 1 & 1 \\
\hline
\end{tabular}

lines and presumably the population, "Texas", contain an apparently simple polymorphism for the control of genotype-environment interaction in ADH activity.

Associations between gene activity and the insertional and deletion variation are less easy to quantify because of the small sample of lines and because the different insertional/deletion variations are in all but one case, $\Delta_{350}$, at low frequency, line specific, and vary in their position on the restriction map. The simplest test for association of this class of DNA polymorphism and genotype-environment interaction is to compare presence or absence of insertion with enzyme activity or response in genotypeenvironment interaction. No association was detected. In order to test for associations of gene action and insertional/deletion variation large samples of variation may be needed.

\section{Discussion}

If gene frequencies in the set of "Texas" inbred lines have not been changed by natural selection during the period of inbreeding, the set of inbred lines can be considered a randomly chosen sample of variation within the "Texas" population. Observations of the variation for several metrical characters and for Adh allozyme frequencies (Birley and Barnes, 1975; Caligari and Mather, 1980) support this assumption. The variation between the lines reported here was detected as restriction endonuclease recognition sites and DNA insertions and deletions. Estimates of variation attributable to restriction sites and insertional/deletion variation are similar to those given by Langley et al. (1982) in a survey of 18 second chromosomes derived directly from four natural populations, though in general values are slightly lower in "Texas". Heterozygosity per nucleotide is here estimated as 0.004 and is similar to estimates of 0.006 and 0.004 obtained for the same DNA segment (Langley et al., 1982) and from nucleotide sequence comparisons of the Adh exons with a sample of 11 independently extracted chromosomes (Kreitman, 1980). For the entire probed region, including both restriction site and insertion/deletion variation, heterozygosity is here estimated as 0.93 (Nei and Tajima, 1981), Langley et al.'s value being 0.95 . That these estimates and the estimates of heterozygosity for insertion/deletion variation (see below) are only slightly lower than those found by the 
latter authors for a natural population(s) is not surprising for reasons of sample size and on the expectations of neutral gene theory. Whilst the population size of "Texas" $(3000)$ is lower than that of a natural population by perhaps a factor of $10^{3}$, the population has been in the laboratory for only 60 generations prior to the extraction of the inbred lines. The number of generations is thence much less than the effective size of "Texas"; even if $\mathrm{Ne} / \mathrm{N}$ is $0 \cdot 5, \mathrm{Ne}=15 \times 10^{2}$. Thus the time for which random genetic drift can act is small compared to $\mathrm{Ne}$ and as shown by Malécot (1948) we can expect only a small loss of variation in "Texas" in the early generations of evolution.

The estimate of heterozygosity per nucleotide obtained by Kreitman (1983) was for the $A d h$ exons and hence reflects not only silent site variation but also the extreme constraint of replacement site polymorphism which was limited solely to the amino acid difference corresponding to the $A d h^{F}$ and $A d h^{s}$ alleles. Whilst it is not yet known whether other coding sequences are present in the region of DNA homologous with the sAS-I probe the estimates of heterozygosity presented here strengthen Kreitman's observation of evolutionary constraint, since it can be presumed that the probed region of DNA must also contain a degree of non-coding DNA.

The restriction site polymorphisms are present in apparently intergenic regions of DNA. The endonuclease Pst-I, polymorphic for a restriction site in this study, was not used in the survey of Langley et al. (1982). Two restriction sites (HindIII $(-3 \cdot 0)$ and Xho-I $(+1 \cdot 2)$ of the remaining three restriction endonuclease polymorphisms observed here share, compared with the study of Langley et al., the same restriction site. Indeed, as noted by Langley et al. (1982), it appears that the same restriction site polymorphisms are common to a number of populations. On the other hand, the variation for DNA insertions and deletions appear to be population specific and this may reflect different evolutionary mechanisms or dynamics associated with this latter class of variation. The high frequency of insertional/ deletion variation for this region, estimated heterozygosity 0.69 (Langley et al.) and 0.57 ("Texas"), appears to be characteristic of populations in general. The positions of the insertions/deletions also appears to be localised into distinct regions some $2-3 \mathrm{~kb}$ on each side of the $A d h$ transcriptional unit and is not associated with restriction site polymorphism. This class of variation has also been observed in other tracts of DNA, for example, human haemoglobin (Higgs, Goodbourn, Wainscoat, Clegg and Weatherall, 1981 ) and is well known in mutant laboratory stocks of Drosophila. Sometimes the insertional variation can be attributable to transposable elements (Green, 1980; Strobel, Dunsmuir and Rubin, 1979) and, in turn, these have been identified in association with the laboratory mutants (Bingham, 1981; Engels and Preston, 1981). At present the nature and origin of the insertions and deletions in the $A d h$ region is unknown. They might even be in regions in which there is a high degree of genetic instability and dysgenic crosses in Drosophila have been associated with the production of DNA insertions through transposition (Green, 1977; Engels, 1981). In this context and as noted by Langley et al. (1982) chromosomes made isogenic by crosses to certain chromosome "balancer-stocks" are liable to induce dysgenic phenomena during their extraction in the laboratory. The recovery of insertional and deletion variations in this study with inbred lines which have not been outcrossed to mutant laboratory stocks suggests 
that they are indeed a natural feature of populations and those insertions which do originate from hybrid dysgenesis do not occur at least in this region of the chromosomes at a sufficiently high frequency for their recovery.

One perhaps surprising feature of the data is that one insert, $\Delta_{350}$, is polymorphic within the two lines 3 and 27 . Although there is a restriction site difference (HindIII $(-3 \cdot 0)$ ) between these two lines there is no further evidence of variation. Indeed these two lines are phenotypically distinct for a number of metrical characters (Birley and Barnes, 1973; Caligari and Mather, 1980) and it is unlikely that the observations are due 'to stock contamination.

The novel feature of this study was the relationship between DNA haplotype and the response of lines in $\mathrm{ADH}$ activity to environmental variance. The linkage disequilibrium between restriction sites on chromosomal markers was strongest for the BamHI/HindIII combination. Moreover the gametic ditypes for this combination of restriction sites show a strong association with genotype-environment interaction. Of course the association may be a chance event, reflecting the ancestry of the chromosome. Indeed for such reasons, levels of linkage disequilibrium might be expected to be particularly high in such a relatively short DNA segment. Nonetheless, the DNA concerned bounds the transcriptional units and whilst any evolutionary, causal relationship between the DNA, marked by the polymorphic restriction sites and the control of $A d h$ activity is not proven, the association by virtue of its relationship with the ADH acitivity phenotype is a potential target for any form of natural selection capable of acting on $\mathrm{ADH}$ activity. One further aspect of the observed linkage disequilibrium was that the associated disequilibria of the HindIII, Bam HI and Xho-I sites with the Pst-I site variation was weak, further strengthening the argument for association of genotype-environment interaction and the BamHI/ HindIII chromosome segment. Another view of the genotype-environment interaction is that it originates from variation of enzyme catalytic properties. However, a study of the Michaelis constants for ADH in the set of inbred lines failed to show any statistically significant differences within $A d h^{s / s}$ or within $A d h^{F / F}$ lines. The only difference was that attributable to the $\mathrm{ADH}-\mathrm{F}$ and $\mathrm{ADH}-\mathrm{S}$ enzyme difference (Sroczynski and Birley, unpublished data).

Although no clear relationship emerged between DNA inserts/deletions and genotype-environment interaction, as discussed earlier in this class of variation is highly heterogeneous. Whether this class of naturally occurring DNA variation affects the ADH phenotype is unknown, however, their of ten low frequency implies they could be very mildly deleterious in fitness. Obviously more detailed survey and in vitro experiment is required. However, this study has shown that a study of naturally occurring variation in DNA may be useful in the study of gene function.

Acknowledgements. I am grateful for the patience and hospitality of members of the Genetics Section, National Institute of Environmental Health Sciences, Research Triangle Park, North Carolina, U.S.A., in particular Dr C. H. Langley and Elizabeth Montgomery, during the course of this study. I also express my gratitude to the Wellcome Trust for a travel aware and to the Royal Society for financial assistance. Computations of molecular weight were carried out on The University of Birmingham's DEC-20 computer interfaced with a Summagraphics digitiser. 


\section{REFERENCES}

ANTONARAKIS, S. E., ORKIN, S. H., KAZAZIAN, H. H. JR., GOFF, S. C., BOEHM, C. D., WABER, P. G., SEXTON, J. P., OSTRER, H., FAIRBANKS, V. F. AND CHAKRAVARTI, A. 1982. Evidence for multiple origins of the $\beta^{E}$-globin gene in Southeast Asia. Proc. Natl. Acad. Sci. USA, 79, 6608-6611.

AVISE, J. C., LANSMAN, R. A. AND SHADE, R. O. 1979. The use of restriction endonucleases to measure mitochondrial DNA sequence relatedness in natural populations. I. Population structure and evolution in the genus Peromyscus. Genetics, 92, 279-295.

Benyajati, C., PlaCe, A. R., POWERs, D. A. AND SOFEr, W. 1981. Alcohol dehydrogenase gene of Drosophila melanogaster: Relationship of intervening sequences to functional domains in the protein. Proc. Natl. Acad. Sci. USA, 78, 2717-2721.

BINGHAM, P. M. 1981. A novel mutant allele at the white locus of Drosophila melanogaster is mutable. Cold Spring Harbor Symp. Quant. Biol. 45, 519-525.

BINGHAM, P., LEVIS, R. AND RUBIN, G. M. 1981. Cloning of DNA sequences from the white locus of Drosophila melanogaster by a novel and general method. Cell, 25, 693-704.

BARNES, B. W. AND BIRLEY, A. J. 1975, Genetical variation for enzyme activity in a population of Drosophila melanogaster. IV. Analysis of alcohol dehydrogenase activity in chromosome substitution lines. Heredity, 40, 51-57.

BIRLEY, A. J. AND BARNES, B. W. 1973. Genetical variation for enzyme activity in a population of Drosophila melanogaster. 1. Extent of the variation for enzyme activity. Heredity, 31, 413-416.

BIRLEY, A. J., MARSON, A. AND PHILlIPS, L. C. 1980. Genetical variation for enzyme activity in a population of Drosophila melanogaster. V. The genetical architecture, as shown by diallel analysis, of alcohol dehydrogenase (ADH) activity. Heredity, 44, 251-268.

BIRLEY, A. J. AND MARSON, A. 1981. Genetical variation for enzyme activity in a population of Drosophila melanogaster. VII. Genotype-environment interaction for alcohol dehydrogenase (ADH) activity. Heredity, 46, 427-441.

BIRLEY, A. J., COUCH, P. AND MARSON, A. 1981. Genetical variation for enzyme activity in a population of Drosophila melanogaster. VI. Molecular variation in the control of alcohol dehydrogenase (ADH) activity. Heredity, 47, 185-196.

CALIGARI, P. D. S. AND MATHER, K. 1980. Dominance, allele frequency and selection in a population of Drosophila melanogaster. Proc. Roy. Soc. B. 208, 163-187.

ENGELS, W. R. 1981. Hybrid dysgenesis in Drosophila and the stochastic loss hypothesis. Cold Spring Harbor Symp. Quant. Biol. 45, 561-565.

ENGELS, W. R. AND PRESTON, C. R. 1981. Identifying P factors in Drosophila by means of chromosome breakage hotspots. Cell, 26, 421-428.

EWENS, W. J., SPIELMAN, R. S. AND HARRIS, H. 1981. Estimation of genetic variation at the DNA level from restriction endonuclease data. Proc. Natl. A cad. Sci. USA, 78, 3748-3750.

GOLDBERG, D. 1980 . Isolation and partial characterisation of the Drosophila alcohol dehydrogenase gene. Proc. Natl. Acad. Sci., USA, 77, 5794-5798.

GREEN, M. M. 1977. Genetic instability in Drosophila melanogaster: de nouo induction of putative insertion elements. Proc. Natl. Acad. Sci., USA, 74, 2978-2980.

GreEN, M. M. 1980. Transposable elements in Drosophila and other Diptera. Ann. Rev. Genet. 14, 109-120.

HIGGS, D. R., GOODBOURNE, S. E. Y., WAINSCOAT, J. S., CLEGG, J. B. AND WEATHERALL, D. J. 1981. Highly variable regions of DNA flank the human $\alpha$ globin genes. Nucleic Acids Res. 9, 4213-4224.

JEFFREYS, A. J. 1979. DNA sequence variants in the $G \gamma-A \gamma, S$ and $\beta$-globin genes of man. Cell, 18, 1-10.

KREITMAN, M. 1983. Nucleotide polymorphism of the alcohol dehydrogenase locus of Drosophila melanogaster. Nature, 304, 412-416.

LANGLEY, C. H., MONTGOMERY, E. AND QUATTLEBAUM, w. 1982. Restriction map variation in the Adh region of Drosophila. Proc. Natl. Acad. Sci. USA, 79, 5631-5635.

LAURIE-AHLbERG, C. C., MARONI, G., BeWley, G. C., LUCCHESI, J. C. AND WeIR, B. S. 1980. Quantitative genetic variation of enzyme activities in natural populations of Drosophila melanogaster. Proc. Natl. Acad. Sci. USA, 77, 1073-1077.

MCDONALD, J. F. AND A Y ALA, F. J. 1978. Genetical and biochemical basis of enzyme activity variation in natural populations. I. Alcohol dehydrogenase in Drosophila melanogaster. Genetics, 89, 371-399.

MCDONNELL, M. W., SIMON, M. N. AND STUDIER, F. W. 1977. Analysis of restriction fragments of T7 DNA and determination of molecular weights by electrophoresis in neutral and alkaline gels. $J$. Mol. Biol. 110, 119-146. 
MALÉCOT, G. 1948. Les Mathématiques de l'Hérédité. Translation (The Mathematics of Heredity) by Yermanos, D. M. (1946). Freeman and Company, San Francisco.

NEI, M. AND TAJIMA, F, 1981. DNA polymorphism detectable by restriction endonucleases. Genetics, 97, 145-163.

ORKIN, S. H., KAZAZIAN, H. H. JR., ANTONARAKIS, S. E., GOFF, S. C., BOEHM, C. D., SEXTON, J. P., WABER, P. G. AND GIARDINA, P. V. J. 1982. Linkage of $\beta$-Thalassaemia mutation and $\beta$-globin polymorphisms with DNA polymorphism in the human $\beta$-globin gene cluster. Nature, 296, 627-631.

PERKINS, J. M. AND JINKS, J. L. 1968. Environmental and genotype-environmental components of variability. III. Multiple lines and crosses. Heredity, 23, 339-356.

POONI, H. S. AND JINKS, J. L. 1980. Non-linear genotype $\times$ environment interactions. II. Statistical models and genetical control. Heredity, 45, 389-400.

RIGBY, P. W. J., DIEKMANN, M., RHODES, C. AND BERG, P. 1977. Labelling DNA to high specific activity in vitro by nick translation with DNA polymerase-I. J. Mol. Biol., 113, 237-251.

SCHAFFER, H. E. AND SEDEROFF, R. R. 1980. Improved estimation of DNA fragment lengths from agarose gels. Anal. Biochem. 115, 113-122.

SHAH, D. M. AND LANGLEY, C. H. 1979. Complex mitochondrial DNA in Drosophila. Nucleic Acids Research, 4, 2949-2960.

SOUTHERN, E. M. 1975. Detection of specific sequences among DNA fragments separated by gel electrophoresis. J. Mol. Biol., 98, 506-517.

STROBEL, E., DUNSMUIR, P. AND RUBIN, G. 1979. Polymorphisms in the chromosomal locations of the elements of the 412, copia and 297 dispersed repeated gene families in Drosophila. Cell, 17, 429-439.

WAHL, G. M., STERN, M. AND STARK, G. R. 1979. Efficient transfer of large DNA from agarose gels to diazobenzyloxymethyl-paper and rapid hybridisation by using dextran sulphate. Proc. Natl. Acad. Sci. USA. 76, 3683-3687. 